American Journal of Agricultural and Biological Sciences 3 (3): 633-638, 2008

ISSN 1557-4989

(C) 2008 Science Publications

\title{
Seed Germination and Seedling Survival of Spartina alterniflora Loisel
}

\author{
Patrick D. Biber and John D. Caldwell \\ Department of Coastal Sciences, The University of Southern Mississippi, \\ 703 East Beach Drive, Ocean Springs, Mississippi 39564, USA
}

\begin{abstract}
Spartina alterniflora (smooth cordgrass) is a widespread intertidal salt marsh plant that is frequently used in coastal restoration projects. Seeds collected in 2004 were tested for seed germination and seedling survival after 6 months of cold seed storage to determine differences among collection locations (experiment 1). Seeds collected in 2005, after Hurricane Katrina, were tested for seed germination and seedling survival from 0 to 15 months of cold seed storage time to determine minimum and maximum storage time and seedling survival rates (experiment 2). Seed germination increased from 1-4 months of cold, wet storage (stratification) and then began to decline. Survival of the seedlings was highest after 2 months of stratification. In experiment 1, seedling size was found to vary widely among seedlings of the same source and age. Seedling height at 22 days after planting ranged from 2-16 cm, despite identical environmental conditions. Selective breeding could target plants with fast early growth characteristics to promote strains that can be raised quickly in a nursery in response to demands for restoration.
\end{abstract}

Key words: Saltmarsh, viability, survival, recalcitrant, stratification

\section{INTRODUCTION}

Spartina alterniflora (smooth cordgrass) is a rhizomatous, perennial grass commonly found in estuarine salt marshes along the Atlantic and Gulf Coasts of the USA. Although this plant is perennial, the aerial stems die back at the end of each growing season. Spartina alterniflora is common in saline or brackish water of the intertidal zone, usually occupying mud- or sand-flats with low to moderate wave energy. The species can tolerate a wide range of environmental conditions, including inundation up to $12 \mathrm{~h}$ a day, $\mathrm{pH}$ values from 4.5 to 8.5 and salinity from 0 to $60 \mathrm{ppt}$, although $10-20$ ppt is optimal ${ }^{[13]}$. Typically $S$. alterniflora dominates the low marsh zone ${ }^{[1]}$, growing from $0.7 \mathrm{~m}$ below mean sea level to approximately mean high water ${ }^{[13]}$. In Mississippi the elevation range is -0.25 to $+0.5 \mathrm{~m}$ mean low water, i.e., the outer fringe of the marsh ${ }^{[8]}$. Spartina alterniflora exhibits diverse growth forms in different salt marsh zones. A tall form occurs along creek banks and drainage channels. Landward of the tall form, an intermediate form occurs, which grades into a stunted form at the marsh interior ${ }^{[21]}$. This species is highly productive, exporting approximately $1300 \mathrm{~g} \mathrm{~m}^{-2}$ of detritus annually to the estuarine system ${ }^{[13,20]}$. Restoration projects commonly use S. alterniflora for erosion control, as well as providing habitat for a diversity of fish and wildlife ${ }^{[20]}$. Plant materials for restoration projects are generally obtained from two sources, a donor wetland site or commercial nurseries. Donor site harvest is generally not recommended because it destroys habitat and transplanting mature plants often results in poor survival ${ }^{[13,23]}$.

Spartina alterniflora can reach sexual maturity in three to four months under favorable conditions ${ }^{[21]}$. Mature plants produce seeds in the fall, with inflorescences of 25-30 cm long emerging at the end of stems in October and November in the northern Gulf of Mexico. Numerous spikes grow along the inflorescence, each holding from twelve to fifteen spikelets or florets. Each spikelet is $5-7 \mathrm{~cm}$ long and may contain a single dried fruit or caryopsis (commonly called a seed). There are approximately 175,000 florets per pound ${ }^{[4]}$. Caryopses require moist chilling for approximately six weeks to germinate, with most germinating in the spring. Seed viability is short-lived (roughly 8 months), therefore, this species does not maintain a persistent seed bank ${ }^{[19]}$. Although S. alterniflora appears to produce a significant number of seeds, most spikelets are empty, or contain a damaged or sterile caryopsis. Furthermore, the caryopsis of $S$. alterniflora is recalcitrant and can not tolerate drying to less than $40 \%$ dry weight either

Corresponding Author: Patrick D. Biber, Department of Coastal Sciences, The University of Southern Mississippi, 703 East Beach Drive, Ocean Springs, Mississippi 39564, USA Tel: 2288724200 Fax: 2288724204 
before or after collection ${ }^{[5,17]}$. Consequently, S. alterniflora seeds are not commercially available ${ }^{[5,14]}$ and germination rates can be highly variable ${ }^{[9,22]}$. Seeds can be collected in bulk quantities in the late fall by hand-stripping the spikes or using a mechanical seed harvester. For experimental purposes, however, it is better to collect seeds by gently shaking the inflorescence to collect only seeds that are fully mature and ready to drop. Collected seeds should be cleaned of foreign materials prior to keeping in moist, wet storage (i.e., stratification) to break dormancy ${ }^{[10]}$. Prolonged seed stratification may lead to reduced germination and seedling survival ${ }^{[17,18]}$. Conversely, shorter stratification time required to break dormancy would be beneficial for nurseries looking to grow these plants from seeds.

The aim of this study was to test S. alterniflora seeds for germination and seedling survival. The specific objectives for experiment 1 were to determine differences in seed collection location, seedling survival and size. The specific objective for experiment 2 was to test the optimal seed stratification period ranging from 0 to 15 months.

\section{MATERIALS AND METHODS}

Spartina alterniflora seeds were collected near the Gulf Coast Research Laboratory $\left(30^{\circ} 23^{\prime} 32.14{ }^{\prime \prime} \mathrm{N}, 88^{\circ}\right.$ $47^{\prime} 54.07^{\prime \prime} \mathrm{W}$ ) in Jackson County, Mississippi. Seeds were collected between 12-18 November 2004 (Experiment 1) and 21 November to 1 December 2005 (Experiment 2) when culms had turned yellow-golden in color. Spikelets were separated from the spikes of the inflorescence by gently hand-stripping the inflorescence and capturing the seeds in a labeled plastic bag. The collected spikelets were cleaned of debris by shaking through sieves and hand-sorting and kept stored in closed plastic bags to reduce water loss. Using a light table, florets containing a caryopsis (full florets) were selected at random to determine average weight. Six subsets of 100 full florets were weighed in 2004 (Experiment 1) and in 2005 three subsets of 1000 full florets were weighed (Experiment 2); differences in mean seed weight between years was determined by a T-test. The cleaned florets were covered with tap water and placed in sealed and labeled plastic bags within one week of collection, then stored in a refrigerator at $4^{\circ} \mathrm{C}$ in order to break their dormancy ${ }^{[15,17]}$ prior to the two germination experiments.

Experiment 1: Collection location study: Seeds were collected from three locations, Ocean Springs East Beach (EB), Davis Bayou Islands (DI), Ocean Springs Weeks Bayou (WB) separated by no more than $1.6 \mathrm{~km}$ in November 2004. After six months stratification at $4^{\circ} \mathrm{C}$, florets were randomly removed from each sample and were visually inspected on a light table to determine if the florets were full (containing a caryopsis) or empty. The number of empty florets set aside during the process of selecting 300 full florets was noted and the percent of full to total florets was determined for each sample (Table 1). Fifty full florets were placed into each of six Petri-dishes $(9.0 \mathrm{~cm}$ diameter) containing two sheets of Whatman \#2 filter paper and wetted with $5 \mathrm{mls}$ tap water to keep seeds moist in the closed Petri-dish. Petri-dishes were opened briefly and the filter paper was wetted or misted daily in order to prevent seeds from drying below the $40 \%$ moisture content that would cause mortality ${ }^{[17]}$. Germination occurred under a bank of four fluorescent lights $\left(75 \mu \mathrm{moL} \mathrm{m}{ }^{-2} \mathrm{sec}^{-1}\right)$ with a temperature range of $21-25^{\circ} \mathrm{C}$. Weekly, the number of seeds that germinated was recorded. After two weeks in the Petri-dishes all seeds, whether they had germinated or not, were transferred to hydrated peat pellets (50 pellets to a plastic bedding tray). Trays were labeled with date planted and collection location to track survival and growth for each site.

Seedlings were kept indoors for 24-36 h to reduce stress from transplanting before being relocated to a greenhouse, where they were watered 2-3 times a week. Seedlings in the greenhouse were counted on a weekly basis for six weeks to determine survival from each location. Seedling survivorship was calculated from the number of seedlings planted, not the initial 300 seeds at the beginning of the experiment (Table 1). The height of the seedlings in the greenhouse was measured on a random selection of 30 plants per location after 22 days in the peat pellets and 36 days after initiating germination in the Petri-dishes. Height was the distance from the soil to the tip of the stem. For statistical analyses the data were tested using JMP 5.0.1 (SAS Institute, Cary, NC) for normality and homogeneity of variances and analyzed by one-way ANOVA, with Tukey's Honestly Significant Difference (HSD) test used post-hoc on significant findings.

Experiment 2: Seed stratification study: Seeds for this study were collected from EB within a radius of $200 \mathrm{~m}$ along the $1-5 \mathrm{~m}$ wide fringe of S. alterniflora. Seeds were germinated between December 2005 (0 month stratification) and March 2007 (15 months at $\left.4^{\circ} \mathrm{C}\right)$. Ten random samples of 10 seeds (100 seeds total) were visually inspected using a light table to assess the percentage of full florets at the beginning of each month (Table 1). Fifty full florets were placed into each of six closed Petri-dishes using the same method as 
Am. J. Agri. \& Biol. Sci., 3 (3): 633-638, 2008

Table 1: Percentage of filled florets for the three locations $(\mathrm{WB}=$ Weeks Bayou, $\mathrm{EB}=$ East Beach, $\mathrm{DI}=$ Davis Island) and stratification times $(0-$ 15 months). Number of viable seeds was based on weekly counts of 300 seeds, not all sprouts survived to planting at week 0 . Seedling survival counted weekly after transplanting to peat pellets in the two experiments

\begin{tabular}{|c|c|c|c|c|c|c|c|c|}
\hline \multirow{2}{*}{$\begin{array}{l}\text { Stratification } \\
\text { time } \\
\text { (months) }\end{array}$} & \multirow{2}{*}{$\begin{array}{l}\text { Sample } \\
\text { location }\end{array}$} & \multirow{2}{*}{$\begin{array}{l}\text { Full } \\
\text { seeds } \\
(\%)\end{array}$} & \multirow{2}{*}{$\begin{array}{l}\text { Viable } \\
\text { seeds } \\
\text { (No.) }\end{array}$} & \multicolumn{5}{|c|}{ No. of seedlings } \\
\hline & & & & Week 0 & Week 1 & Week 2 & Week $3^{\mathrm{a}}$ & Week 6 \\
\hline \multicolumn{9}{|c|}{ Experiment 1-collection location (2004 seeds) } \\
\hline 6 & WB & 33 & 247 & 157 & 116 & 115 & 111 & 105 \\
\hline 6 & DI & 33 & 258 & 219 & 207 & 204 & 204 & 202 \\
\hline 6 & $\mathrm{~EB}$ & 53 & 254 & 223 & 183 & 172 & 173 & 168 \\
\hline \multicolumn{9}{|c|}{ Experiment 2-seed stratification (2005 seeds) } \\
\hline 0 & EB & 15 & 1 & 0 & 0 & 0 & 0 & \\
\hline 1 & EB & 26 & 62 & 56 & 42 & 27 & 18 & \\
\hline 2 & EB & 20 & 58 & 58 & 52 & 48 & 39 & \\
\hline 3 & EB & 15 & 104 & 95 & 39 & 25 & 12 & \\
\hline 4 & EB & 21 & 101 & 101 & 39 & 26 & 24 & \\
\hline 5 & EB & 15 & 85 & 83 & 26 & 7 & 7 & \\
\hline 6 & EB & 23 & 17 & 16 & 10 & 4 & 3 & \\
\hline 7 & EB & 18 & 61 & 60 & 10 & 3 & 1 & \\
\hline 8 & EB & 19 & 36 & 36 & 3 & 2 & 1 & \\
\hline 9 & EB & 17 & 32 & 32 & 10 & 1 & 0 & \\
\hline 10 & EB & 16 & 11 & 11 & 9 & 2 & 1 & \\
\hline 11 & EB & $\mathrm{n} / \mathrm{a}$ & 4 & 4 & 2 & 0 & 0 & \\
\hline 12 & EB & $\mathrm{n} / \mathrm{a}$ & 1 & 1 & 1 & 1 & 1 & \\
\hline 13 & EB & $\mathrm{n} / \mathrm{a}$ & 0 & 0 & 0 & 0 & 0 & \\
\hline 14 & EB & $\mathrm{n} / \mathrm{a}$ & 0 & 0 & 0 & 0 & 0 & \\
\hline 15 & EB & $\mathrm{n} / \mathrm{a}$ & 0 & 0 & 0 & 0 & 0 & \\
\hline
\end{tabular}

for experiment 1 . Seeds were allowed to germinate for three weeks in an incubator kept on a 12: 12 h day: night photoperiod at temperatures between $25-30^{\circ} \mathrm{C}$. After three weeks, only seeds that germinated (viable seeds) were planted into hydrated peat pellets. Peat pellets with sprouted seedlings were placed into plastic bedding containers along with 1-2 $\mathrm{cm}$ of tap water and then put back into the incubator under fluorescent lights. Light intensity was measured with a LICOR (Lincoln, NE) cosine quantum sensor (LI-190) and ranged from $20-90 \mu \mathrm{moL} \mathrm{m}{ }^{-2} \mathrm{~s}^{-1}$, depending upon the distance of the seedlings from the light source. The germinated seedlings were then observed weekly over 21 days to determine their survival after planting. The planted seedlings were watered with tap water every 1-2 days. After three weeks the remaining seedlings were moved from the chamber to the greenhouse. Data on germination and survival were analyzed as for experiment 1 .

\section{RESULTS AND DISCUSSION}

There was more than a $50 \%$ decrease in spikelet weight in 2005 when compared to the 2004 seeds. Spikelet weight in 2004 averaged $3.58( \pm 0.207) \mathrm{mg}$ and in 2005 spikelet weight averaged $1.57 \mathrm{mg}( \pm 0.001)$, a significant decrease (t-test $\left.t_{2 \mathrm{df}}=5.793, \mathrm{p}=0.0143\right)$. The average number of florets containing a caryopsis was $53 \%$ for 2004 , compared to $18.6 \%$ in 2005 for seeds collected from EB (Table 1). Hurricane Katrina may have affected seed production due to both direct damage to plants (from storm surge, waves and wind), as well as indirectly due to the four month drought following the storm, during the period when seeds were produced.

\section{Seed germination}

Experiment 1: Viability based on 300 full florets tested per collection location was $86 \%$ DI, $85 \%$ EB and $82 \%$ WB (Fig. 1A). Mean viability was not significantly different among the three locations (one-way fixed factor ANOVA, $\left.\mathrm{F}_{2,17}=0.4501, \mathrm{p}=0.6459\right)$. After 2 weeks in the Petri-dishes, $52 \%$ of seeds were planted from WB and $73-74 \%$ for DI and EB (Table 1) as some mortality of sprouts occurred prior to planting.

Experiment 2: Stratification time significantly affected seed germination (one-way fixed factor ANOVA, $\left.\mathrm{F}_{15,95}=72.9515, \mathrm{p}<0.0001\right)$. Germination of full florets increased from 1-4 months of stratification and then declined. After only 1 month of stratification, germination after 3 weeks in the Petri-dishes was 19\% (Fig. 2). The maximum germination after 3 weeks was $34 \%$ in seeds stratified for 3-4 months (Fig. 2). There was no statistical difference in mean germination of seeds between 2-5 and 7 months stratification. Germination was significantly lower in month 6 of the experiment, only $5 \%$ compared to $28 \%$ for the prior 

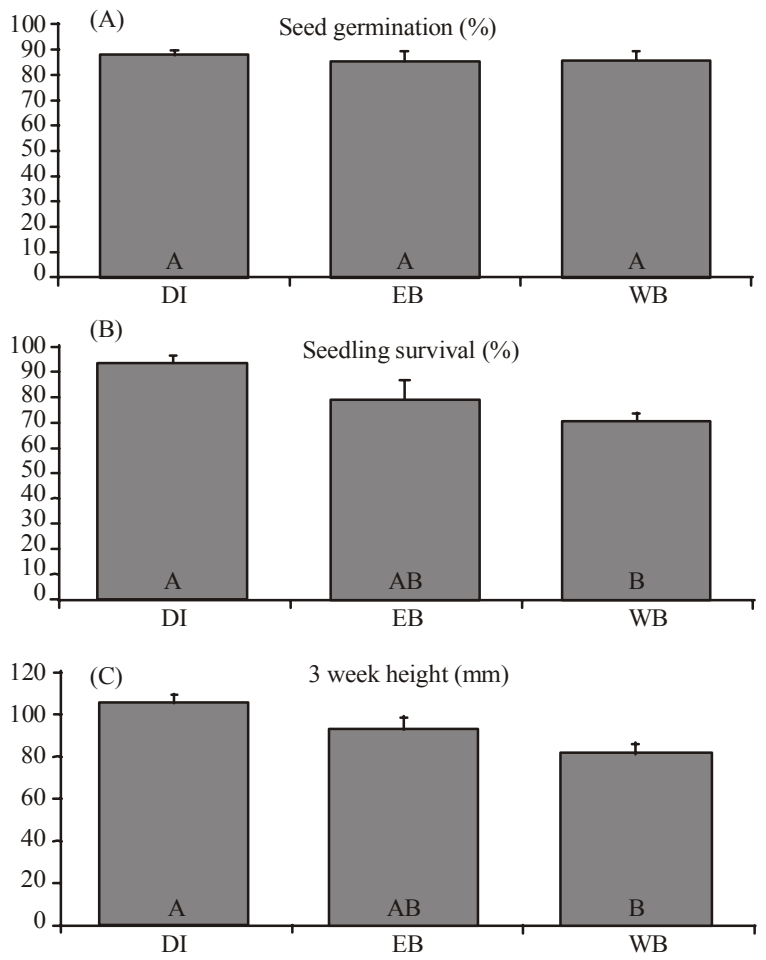

Fig. 1: Results of Experiment 1 using Spartina alterniflora seeds collected from 3 locations and stratified for 6 months. (A): Percent of seeds $($ mean \pm SE) that germinated after 2 weeks. (B): Percent of seedlings (mean \pm SE) that survived 3 weeks after planting. (C): Seedling size (mean \pm SE) at 22 days after planting. Tukey's post-hoc test shows means that are not significantly different grouped by the same letter

month and 20\% for the subsequent month (Fig. 2, Table 1). After 12 months of stratification, germination dropped to less than $1 \%$ (Fig. 2).

\section{Seedling survival}

Experiment 1: Seedlings from all 3 locations had $>70 \%$ survival 3 weeks after planting (Fig. 1B). Mean survival of the planted seedlings after 3 weeks was significantly greater at DI than WB (one-way fixed factor ANOVA, $\left.\mathrm{F}_{2,17}=5.676, \mathrm{p}=0.0146\right)$. After 6 weeks, survival ranged from $67 \%$ (WB) to $92 \%$ (DI) of the seedlings planted (Table 1).

Experiment 2: Seedling survival after transplanting to the peat pellets was highly variable but declined over the 3 weeks of observations (Table 1). Seedlings were only followed for 3 weeks in experiment 2 as

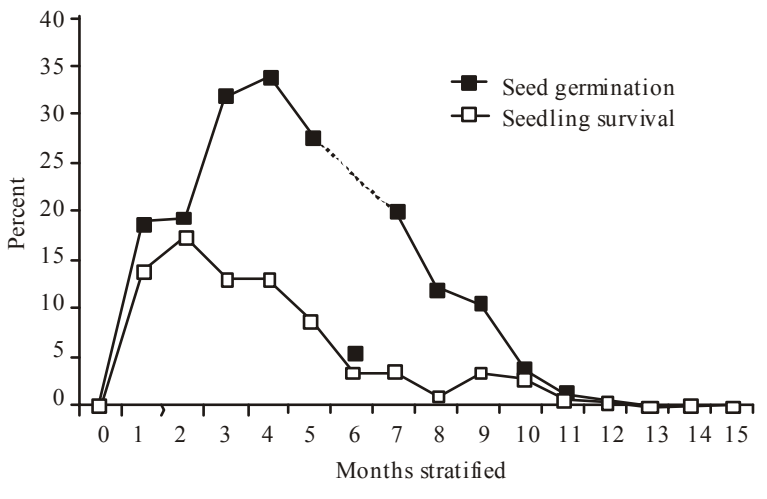

Fig. 2: Results of Experiment 2 with Spartina alterniflora seeds wet stratified at $4{ }^{\circ} \mathrm{C}$ in the dark from 0-15 months. Percent of seeds $(\mathrm{n}=300)$ germinated after 3 weeks (filled squares) and percent of seedlings surviving at 3 weeks after planting (open squares). Germination at 6 months was negatively affected by a temporary incubator failure, so expected germination for that month is indicated by the dashed line segment

conditions in the incubation chamber did not appear to be favorable for growth due to low light levels. Nonetheless, the data show decreasing seedling survival with longer seed stratification time (Fig. 2). Survival of seeds to 3 weeks after planting was highest in seeds stratified for 1-4 months (Fig. 2, Table 1). Stratification longer than 4 months resulted in less than 10 seedlings surviving to 2 weeks after planting (Table 1).

Plant height: Plant height in Experiment 1 ranged from 2.2 to $15.7 \mathrm{~cm}$ for plants after 22 days in the peat pellets and 36 days after placing the seeds in Petri-dishes for germination. Mean seedling height at this time was significantly different among locations (one-way fixed factor ANOVA, $\mathrm{F}_{2,89}=4.5712, \mathrm{p}=0.013$ ) with $8 \mathrm{~cm}$ for seedlings from $\mathrm{WB}, 9.2 \mathrm{~cm}$ for $\mathrm{EB}$ and $10.3 \mathrm{~cm}$ for DI (Fig. 1C). The range of seedling heights observed suggests strong differences among seeds within and among collections.

Germination of Spartina alterniflora seeds collected in the fall of 2004 and 2005 varied by year, location and date of collection. Filled florets from 2005 had a lower weight than those from 2004 and the percent of florets that contained a caryopsis was also lower in 2005 than in 2004. The combination of fewer filled seeds and lower weight in 2005 is presumably a result of stress from Hurricane Katrina (August 29, 2005) and the subsequent drought through the rest of that year. S. alterniflora seeds are recalcitrant. If the 
seeds are maturing on plants that do not receive sufficient water each day (either by tides or rain), the seed moisture will decline while the seeds are on the mother plant and the seeds can die on the mother plant $^{[5,17,18]}$.

Collection location had no effect on germination, but did appear to influence seedling survival and growth. Seeds collected in 2004 from Davis Island survived better and grew taller than those from Weeks Bayou. It is possible the strain of S. alterniflora planted during the 1978 restoration of Davis Island was the 'Vermilion' cultivar, which may be different than the native genotype found at East Beach and Weeks Bayou $^{[6,23]}$. Seeds from Weeks Bayou may also have been negatively affected by the ergot fungus, Claviceps purpurea, which occurs on S. alterniflora in the southeastern USA. Ergot infects flower parts and replaces grain with sclerotia (a hardened mass of filaments), which potentially reduces seed production $^{[11]}$. It is important to select collection locations where this fungus is less prevalent and to carefully clean batches of seeds to remove those that are infected.

Collection date also affects seed maturity; the collection window for the best seeds that are fully ripe may be less than 7 days for $S$. alterniflora in Mississippi. Seeds collected prior to this period will not all be mature, while collection past this date will miss those seeds that have already dropped off the inflorescence and therefore germination percentage may also drop. Ripe seeds are typically lost over a few days when the inflorescence shatters (i.e., drops all it's seeds) as a result of strong winds and cold temperatures associated with early winter cold fronts penetrating south to the Gulf of Mexico.

Cold and wet storage (stratification) is a must to break dormancy and promote germination of seeds in S. alterniflora. A minimum of $4-8$ weeks at $4{ }^{\circ} \mathrm{C}$ appears necessary ${ }^{[4]}$. Stratification beyond 4 months results in reduced germination and seedling survival (Seneca 1974), also confirmed by this study. This period mirrors winter cold temperatures experienced by the seeds in the soil or floating in the near-shore waters as they dispers $\mathrm{e}^{[17,18]}$. Dormancy is broken by the cumulative cold period, rather than the minimum temperature ${ }^{[3,22]}$. Percent viability of S. alterniflora was previously found to be $8 \%$ from Charleston, SC in 1971 and $12 \%$ from Stonington, CN in 1971 using tetrazolium chloride on seeds stratified for 30 days ${ }^{[22]}$, whereas the viability of S. alterniflora collected from Ocean Springs, MS in 2005 was $21 \%$ after 1 month stratification.

Germination can occur in the absence of light, after about 4-5 months of stratification and often the colorless plumule that develops can be used as an indication of when the seeds are ready to remove from cold storage and place under lights. Seed germination under lights was observed after a few days in the Petridishes and tapered off after 2-3 weeks. Late germinating seeds were noted to have poorer survival. Seedling survival in the peat pellets appeared to be influenced by light intensity. More light was noted to relate to higher survival. Seedlings in the greenhouse (Experiment 1) had higher week-to-week survival than those in the incubation chamber (Experiment 2), where low light levels may have been insufficient to support growth after seed storage reserves were used up. Seedlings in this study appeared to require at least 12 moles day ${ }^{-1}$ of light to grow after 7-10 days when they had used up the stored resources in the seed. This light level can be provided by a longer day-length (e.g., 18 L: 6 D) or by moving trays closer to the fluorescence bulbs.

Survival of the seedlings is an important factor to consider immediately after planting. At this time the seedlings are highly susceptible to rapid changes in relative humidity (desiccation), temperatures and light levels. The reasons for this include the lack of welldeveloped protective waxy cuticle ${ }^{[12]}$, stomata which have been shown to be sluggish, responding to decreased relative humidity too slowly to prevent desiccation $^{[2]}$ and physiological processes required to up-regulate photosynthetic cells and organelles including photo-protective pathways of energy dissipation $^{[7]}$. Therefore, it is imperative that seedlings transferred from the very humid germination environment be carefully acclimated to the growing conditions over a period of days to weeks to reduce transplant mortality. After 2-3 weeks acclimation, the seedlings will be sufficiently mature to tolerate the ambient conditions in the greenhouse.

Seedling size was found to vary widely within cohorts of the same source and age in this study and has been previously reported ${ }^{[16]}$. Seedling height at approximately 3 weeks after planting ranged from 2-16 cm, despite the same environmental conditions. Selective breeding could target plants with fast early growth characteristics to promote strains that can be transplanted at restoration sites within a few months of germination.

\section{ACKNOWLEDGMENT}

This research was supported by a Tidelands Trust Fund grant (FY2005-M205-3) through the Mississippi Department of Marine Resources. We thank A. Karels and B. Joachim for their efforts in data collection and 
plant maintenance and L. Singelton for edits to the manuscript.

\section{REFERENCES}

1. Bertness, M.D., 1991. Zonation of Spartina patens and Spartina alterniflora in a New England salt marsh. Ecology, 72: 138-148.

2. Blanke, M.M. and A.R. Belcher, 1989. Stomata of apple leaves cultured in vitro. Plant Cell. Tissue Organ. Cult., 19: 85-89.

3. Broome, S.W., W.W. Woodhouse and E.D. Seneca, 1974. Propagation of smooth cordgrass, Spartina alterniflora, from seed in North Carolina. Chesapeake Sci., 15: 214-221.

4. Bush, T., 2002. Spartina alterniflora Plant Fact Sheet. United States Department of Agriculture, Natural Resources Conservation Service, Rose Lake Plant Materials Center, East Lansing, MI, USA.

5. Cohn, M.A. and J.H. Chappell, 2007. Recalcitrance and dormancy in smooth cordgrass. Louisiana Agric., 50: 25.

6. Daehler, C.C., 1999. Inbreeding depression in smooth cordgrass (Spartina alterniflora, Poaceae) invading San Francisco bay. Am. J. Bot., 86: 131-139.

7. Demmig-Adams, B., W.W. Adams III and A. Mattoo, 2006. Photoprotection, Photoinhibition, Gene Regulation and Environment. Springer, Dordrecht, The Netherlands, pp: 369.

8. Eleuterius, L.N., 1973. The marshes of Mississippi. In: Cooperative Gulf of Mexico Estuarine Inventory and Study, Mississippi, J.Y. Christmas (Ed.). Gulf Coast Research Laboratory, Ocean Springs, MS, USA., pp: 147-189.

9. Fang, X., P.K. Subudhi, B.C. Venuto and S.A. Harrison, 2004. Mode of pollination, pollen germination and seed set in smooth cordgrass (Spartina alterniflora). Int. J. Plant Sci., 165: 395-401.

10. Garbisch, E.W. and S.M. McIninch, 1992. Seed information for wetland plant species of the northeast United States. Restorat. Manage. Notes, 10: 85-86.

11. Gessner, R.V., 1978. Spartina alterniflora seed fungi. Can. J. Bot., 56: 2942-2947.

12. Kyte, L. and J. Kleyn, 1998. Plants from Test Tubes: An Introduction to Micropropagation. 3rd Edn. Timber Press, Inc. Portland, OR, USA., pp: 240.
13. Landin, M.C., 1991. Growth Habits and Other Considerations of Smooth Cordgrass, Spartina alterniflora Loisel. In: Spartina Workshop Record, T.F. Mumford, Jr., P. Peyton, J.R. Sayce and S. Harbell (Eds.). Washington Sea Grant Program, University of Washington, Seattle, WA, USA., pp: 15-20.

14. Materne, M., 2000. Spartina alterniflora Plant Guide. United States Department of Agriculture, Natural Resources Conservation Service, Louisiana State Office, Plant Materials, Baton Rouge, LA, USA.

15. McIninch, S.M. and E.W. Garbisch, 2004. Propagation of Wetland Plants: Herbaceous Plants, Shrubs and Trees. Environmental Concern Inc., St. Michaels, MD, pp: 350.

16. Mooring, M.T., A.W. Cooper and E.D. Seneca, 1971. Seed germination response and evidence for height ecophenes in Spartina alterniflora from North Carolina. Am. J. Bot., 58: 48-55.

17. Plyler, D.B. and K.M. Carrick, 1993. Site-specific seed dormancy in Spartina alterniflora. Am. J. Bot., 80: 752-756.

18. Plyler, D.B. and T.E. Proseus, 1996. A comparison of the seed dormancy characteristics of Spartina patens and Spartina alterniflora (Poaceae). Am. J. Bot., 83: 11-14.

19. Sayce, K. and T.F. Mumford, Jr., 1990. Identifying the Spartina species. In: Spartina Workshop Record, T.F. Mumford, Jr., P. Peyton, J.R. Sayce and S. Harbell (Eds.). Washington Sea Grant Program, University of Washington, Seattle, WA, USA., pp: 9-14.

20. Simenstad, C.A. and R.M. Thom, 1995. Spartina alterniflora (smooth cordgrass) as an invasive halophyte in Pacific Northwest estuaries. Hortus Northwest, 6: 9-12, 38-40.

21. Smart, R.M., 1982. Distribution and Environmental Control of Productivity and Growth form of Spartina alterniflora (Loisel.). D.N. Sen and K.S. Rajpurohit, (Eds.). Tasks for Vegetation Science, Vol. 2. Dr. W. Junk Publishers, The Hague, The Netherlands, pp: 127-142.

22. Stalter, R., 1973. Seed viability in two Atlantic coast populations of Spartina alterniflora. Castanea, 38: 110-113.

23. Travis, S.E., C.E. Proffitt and K. Ritland, 2004. Population structure and inbreeding vary with successional stage in created Spartina alterniflora marshes. Ecol. Appl., 14: 1189-1202. 